\title{
Exposure as Collected Directionality
}

National Cancer Institute

\section{Source}

National Cancer Institute. Exposure as Collected Directionality. NCI Thesaurus. Code C117490.

A qualifier for the direction on the body the collected exposure assessment is performed. 